\title{
Resonance ionization scheme development for europium
}

\author{
K. Chrysalidis ${ }^{* a, b}$. T. Day Goodacre ${ }^{\text {a,c }}$. \\ V.N. Fedosseev ${ }^{\mathrm{a}}$ - B.A. Marsh ${ }^{\mathrm{a}}$ - P. Naubereit ${ }^{\mathrm{b}}$ \\ S. Rothe $^{\mathrm{a}}$. C. Seiffert ${ }^{\mathrm{a}}$. T. Kron ${ }^{\mathrm{b}}$ - K. Wendt ${ }^{\mathrm{b}}$
}

January 23, 2017

\begin{abstract}
Odd-parity autoionizing states of europium have been investigated by resonance ionization spectroscopy via two-step, two-resonance excitations. The aim of this work was to establish ionization schemes specifically suited for europium ion beam production using the ISOLDE Resonance Ionization Laser Ion Source (RILIS). 13 new RILIS-compatible ionization schemes are proposed. The scheme development was the first application of the Photo Ionization Spectroscopy Apparatus (PISA) which has recently been integrated into the RILIS setup.
\end{abstract}

Keywords Resonance laser ionization · Laser ion source · RILIS · Europium · Ionization scheme development $\cdot$ Autoionizing states

\section{Introduction}

The Resonance Ionization Laser Ion Source (RILIS) [1,2,3] at the ISOLDE radioactive beam facility at CERN [4] is the most intensively used ion source, providing $>75 \%$ of the ion beams in 2016. The RILIS is based on the principle of stepwise laser resonance ionization which is an element (and in some cases isotope or isomer) selective process. Europium belongs to the lanthanides which have ionization potentials (IP) of relatively low values in the range $5.4-6.3 \mathrm{eV}$ [5]. Europium, with an IP of $5.67 \mathrm{eV}$ [6], has therefore been produced at ISOLDE with a standard surface ion source [7] in the past. The effective ionization potential of europium lies at $\sim 5.60 \mathrm{eV}^{1}$, which is slightly higher than the effective ionization potential of e.g. samarium $(\sim 5.55 \mathrm{eV})$. For samarium earlier measurements during on-line beam production at ISOLDE have shown, that an enhancement from laser to surface ionization of a factor of 6 can be reached (target at $2000^{\circ} \mathrm{C}$, ion source at $1600^{\circ} \mathrm{C}$ ). Another

${ }^{\mathrm{a}}$ CERN, CH-1211 Geneva 23, Switzerland

${ }^{b}$ Institiut für Physik, Johannes Gutenberg-Universität, D-55099 Mainz, Germany

${ }^{c}$ School of Physics and Astronomy, The University of Manchester, Manchester, M13 9PL, United Kingdom

*E-mail: katerina.chrysalidis@cern.ch

1 the effective ionization potentials have been calculated for a temperature of $2000^{\circ} \mathrm{C}$, according to $\mathrm{IP}_{\text {effective }}=\mathrm{IP}-k T \ln \left(\frac{Q_{i}}{Q_{a}}\right)$, where $k$ is the Boltzmann constant, $T$ is the temperature and $Q_{i, a}$ are the partition functions of the ion and atom respectively (see $[8,9]$ ) 
rare earth element for which resonance laser ionization has been used in the past for on-line applications is neodymium with an effective ionization potential of $\sim 5.43 \mathrm{eV}$. Depending on the target and ion source temperatures, laser to surface ionization enhancement factors of 3 (target at $1800^{\circ} \mathrm{C}$, ion source at $2130^{\circ} \mathrm{C}$ ) up to 20 have been observed (target at $1800^{\circ} \mathrm{C}$, ion source at $1930^{\circ} \mathrm{C}$ ). It is therefore reasonable to expect that a significant enhancement factor in the ion rate of europium should be seen when applying an efficient laser ionization scheme in a standard ISOLDE hot-cavity environment. In addition the isobar purity can be further enhanced if the RILIS is used in conjunction with surface ion suppression methods, e.g. reduced ion source temperatures, fast beam gating [10,11], low work function cavities [12] or the Laser Ion Source Trap (LIST) [13].

Presently several resonance laser ionization schemes for europium exist, making use of either three step schemes [14] or two step schemes [15]. In both cases dye laser were used, where the two step schemes have made use of UV pumped dye lasers, emitting light in the blue to green spectral range. None of the existing schemes are specifically well suited to convenient operation of the current RILIS laser setup (see section 2), because they either require a longer setup time (three-step excitation) or operation with UV pumped dyes. This work is the first application of a newly commissioned off-line atomic beam unit, the so-called Photo Ionization Spectroscopy Apparatus (PISA) $[16,17]$. This device was used in combination with the ISOLDE RILIS laser system in order to develop convenient and effective RILIS ionization schemes for europium.

\section{Experimental method}

The current laser setup of the RILIS (see [2]) consists on the one hand of three tunable, commercial dye lasers (2x CREDO from Sirah Lasertechnik GmbH and $1 \times$ MSS from DMK Laser Microsystems), pumped by a Nd:YAG (532 nm and $355 \mathrm{~nm}$ ) laser from Edgewave $\mathrm{GmbH}$. On the other hand there are three solid state Titanium:Sapphire (Ti:Sa) lasers, based on the design by Mainz university $(2 \times$ Z-cavities $[18,19]$ and 1 x tunable grating Ti:Sa [20]) available which are pumped by two Photonics Industries DM-60 frequency doubled $\mathrm{Nd}$ :YAG lasers. Additionally a Blaze laser from Coherent (frequency doubled Nd: $\mathrm{YVO}_{4}$, $532 \mathrm{~nm}$ ) is available and most commonly used for RILIS ionization schemes which employ a non-resonant last step for ionization. All lasers operate at a repetition rate of $10 \mathrm{kHz}$. The laser beams pass through telescopes on the laser table (as the last focusing elements) and are usually directed into the ion source of one of the two ISOLDE target stations (see e.g. [2]). For this work the laser beams were instead sent past the GPS launch mirrors (see Figure 1) and directed into the PISA. Spacial overlap at the interaction region was achieved by overlapping the laser beams before and after the laser windows of the PISA. The diameter of the laser beams at the laser-atom interaction region was $3-4 \mathrm{~mm}$. 


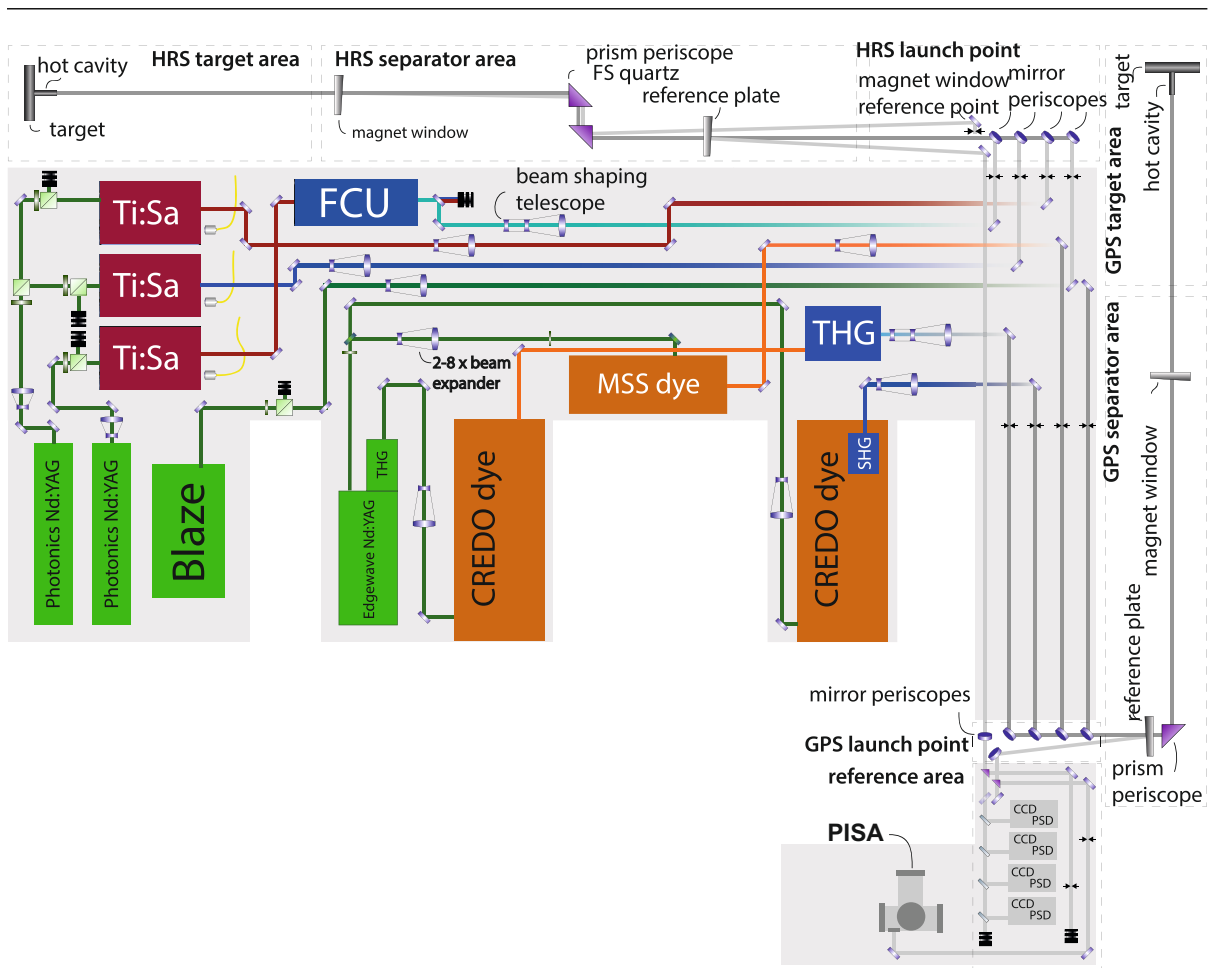

Fig. 1 Current layout of the ISOLDE RILIS laser setup. The PISA is installed on a dedicated laser table, next to the reference and observation system (bottom right). Picture adapted from [2].

The typical approach for RILIS scheme development is described in [21] among others. The scheme development for the europium was performed making use of the PISA, an atomic beam unit, which was developed at Mainz University by T. Kron [22,23]. It consists of an oven tube, indirectly heated by a heating coil, a surface ion repeller which reduces the surface ionized background from the oven and a plate for steering the ions towards a lens which focuses it onto a secondary electron multiplier (SEM). The setup of the PISA is depicted in Figure 2, together with a simulation of the electric field lines and the resulting trajectory of the ions. The PISA has been recently installed in the laser laboratory of the ISOLDE RILIS [17], its position in the overall setup can be seen in Figure 1. The main advantage of the PISA is that initial scheme development can be performed during periods when the ISOLDE mass separators are not available for operation. Making use of the full RILIS lasers ensures that the resulting schemes are well adapted for the wavelength range offered by the RILIS laser setup. An europium sample $\left(\mathrm{Eu}_{2} \mathrm{O}_{3}\right.$ in $5 \% \mathrm{HNO}_{3}$ on a tantalum foil) was inserted into the oven tube and evaporated. According to [24] a temperature of $620^{\circ} \mathrm{C}$ is needed in order to achieve a vapor pressure of $>1.3 \times 10^{-2} \mathrm{mBar}$ for europium, therefore the oven was heated to a temperature of $\sim 750^{\circ} \mathrm{C}$. A tantalum oven was used for this work as the lanthanides are known to react with graphite. 

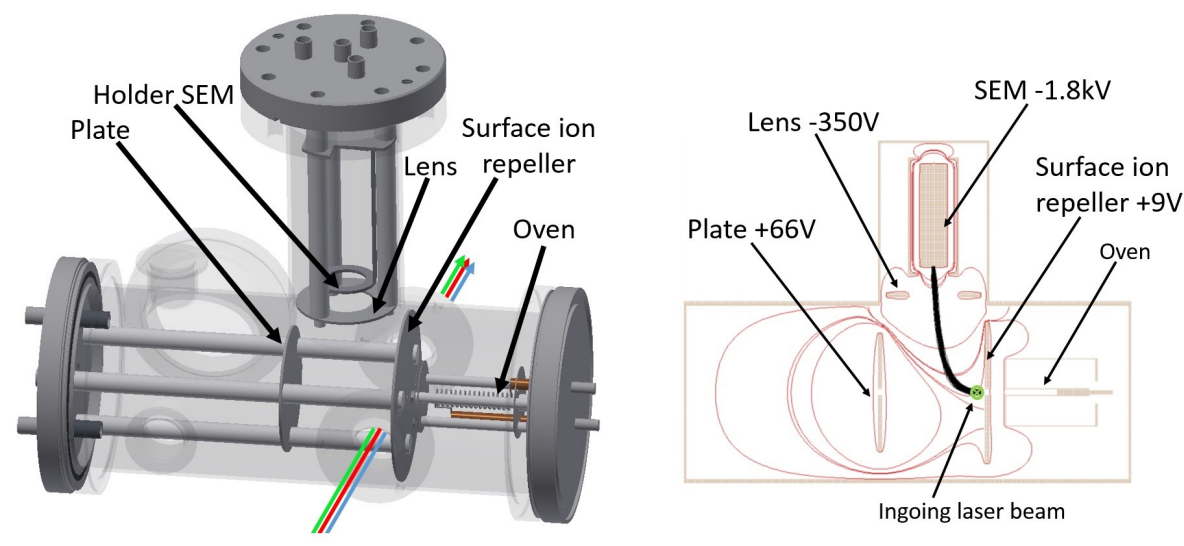

Fig. 2 A drawing of the PISA is depicted on the left next to a simulation of the electric field potentials and the resulting ion beam trajectory (drawings from [22], adjusted).

\section{Results}

The first resonant step was chosen from literature. It is a transition from the ground state $4 f^{7} 6 s^{2} a^{8} S_{7 / 2}^{0}$ to the $4 f^{6} 5 d 6 s^{2}{ }^{8} P_{9 / 2}$ excited state at $32130.25 \mathrm{~cm}^{-1}$ [25]. Several frequency scans were performed in order to find a suitable, resonant transition to an autoionizing state. The scans in a wavelength range of 544 to $730 \mathrm{~nm}$ were performed with different laser dyes (ethanol solvent) which are listed in Table 1.

Table 1 Dyes used for second step scans of europium

\begin{tabular}{c|c} 
Dye name & Wavelength range $[\mathrm{nm}]$ \\
\hline Pyridin 1 & $660-730$ \\
DCM & $610-670$ \\
Rhodamine B & $586-627$ \\
Rhodamine 6G & $557-588$ \\
Fluorescein 548 & $544-559$
\end{tabular}

Additionally the grating Ti:Sa was scanned in a wavelength range of about 714 to $918 \mathrm{~nm}$. This gave the possibility of scanning above and below the IP $=45734.74 \mathrm{~cm}^{-1}$ [6], revealing some additional transitions to autoionizing states (AIS) and Rydberg levels. The analysis of the Rydberg levels leading to the ionization potential will be the scope of a future publication.

A complete outline of the scans is given in Figure 3, where the ion currents for each scan have been scaled in order to gain a better overview. The transition energies $v_{\text {AIS }}$ of the AIS are given in Table 2 along with the relative intensities for each scanned region and the total energy $\left(E_{\mathrm{AIS}}=E_{1}+v_{\mathrm{AIS}}\right)$. The individual errors of the transitions result from the fitting errors and the error of the wavemeter which was assumed to be a systematic error 


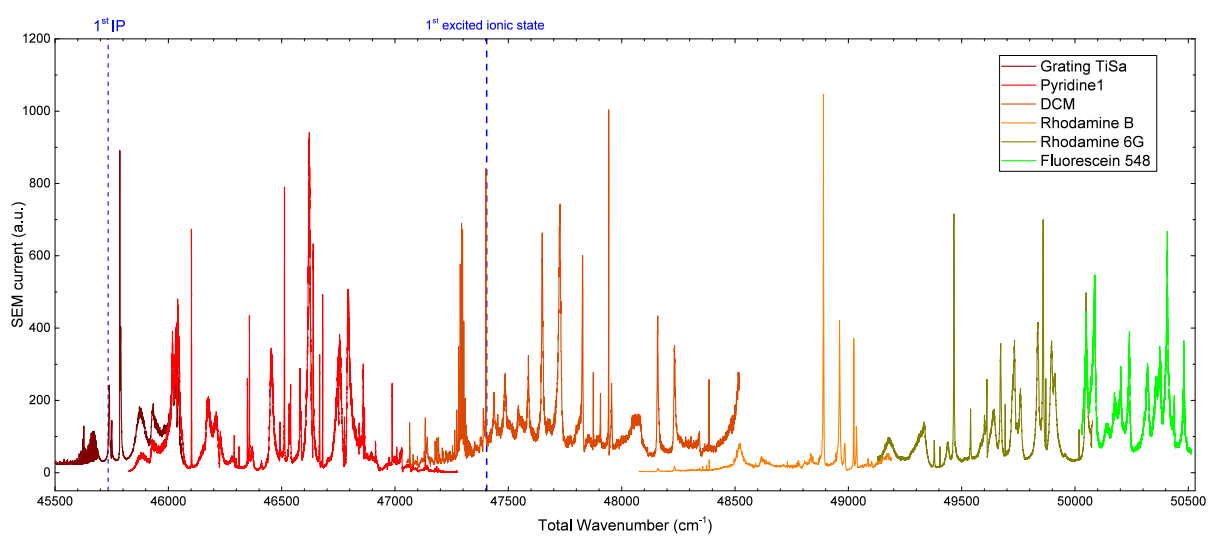

Fig. 3 Overview of the second (final) step scans performed in the PISA.

of $\Delta E_{\mathrm{wm}}=0.03 \mathrm{~cm}^{-1}$. Each region was scanned in two directions, so that each resonance was measured two times. The final value for the transitions $v_{\text {AIS }}$ are therefore a result of the weighted mean value of at least two measurements (up to four in the case of resonances observed in the overlapping regions of the scanning ranges). For determining the relative intensities, the lowest peak in each of the scanned wavelength regions was chosen as reference, so that the lowest intensity is 1 and the numbers grow for higher intensities. It should be noted that due to time restrictions and the multitude of observed AIS there were no attempts to verify the saturation of the different transitions. Therefore a comparison of the relative intensities of the different scanning ranges has not been attempted. Some of the observed AIS have already been reported in the paper by S. Bhattachryya et al. [26] and have been marked with an *. Additionally peaks that have been observed in more than one scan are presented in italic characters.

Table 2: Transitions $v_{\text {AIS }}$ to autoionizing states observed from the laserexcited europium level $4 f^{6} 5 d 6 s^{2}{ }^{8} P_{9 / 2}$. The italic characters indicate that the AIS were found in two different spectra (relative intensities are given for both recorded spectra). The * indicate that the levels have been observed in [26] and match the results from this work within their error margin.

\begin{tabular}{c|c|l} 
Transition energy $v_{\mathrm{AIS}}\left[\mathrm{cm}^{-1}\right]$ & Relative intensity & Total energy $E_{\mathrm{AIS}}\left[\mathrm{cm}^{-1}\right]$ \\
\hline $13608.39 \pm 0.08$ & 3 & 45738.64 \\
$13614.72 \pm 0.09$ & 1 & 45744.97 \\
$13620.13 \pm 0.07$ & 2 & 45750.38 \\
$13655.85 \pm 0.15$ & 12 & $45786.10^{*}$ \\
$13659.31 \pm 0.11$ & 5 & $45789.56^{*}$ \\
$13739.46 \pm 0.35$ & 2,1 & 45869.71 \\
$13794.99 \pm 0.21$ & 1,1 & 45925.24 \\
$13887.04 \pm 0.17$ & 4,6 & 46017.29 \\
$13908.18 \pm 0.20$ & 4,9 & 46038.43 \\
$13911.20 \pm 1.01$ & 3 & 46041.45 \\
\hline $13971.76 \pm 0.03$ & 17 & $46102.01^{*}$
\end{tabular}




\begin{tabular}{|c|c|c|}
\hline $14040.58 \pm 0.20$ & 4 & 46170.83 \\
\hline $14089.89 \pm 0.27$ & 3 & 46220.14 \\
\hline $14097.50 \pm 0.17$ & 2 & 46227.75 \\
\hline $14160.47 \pm 0.04$ & 2 & 46290.72 \\
\hline $14168.62 \pm 0.02$ & 1 & 46298.87 \\
\hline $14181.27 \pm 0.03$ & 1 & 46311.52 \\
\hline $14218.37 \pm 0.02$ & 6 & $46348.62^{*}$ \\
\hline $14220.99 \pm 0.03$ & 1 & $46351.24^{*}$ \\
\hline $14227.41 \pm 0.02$ & 9 & $46357.66^{*}$ \\
\hline $14241.18 \pm 0.20$ & 1 & $46371.43^{*}$ \\
\hline $14322.95 \pm 0.08$ & 7 & $46453.20^{*}$ \\
\hline $14361.92 \pm 0.05$ & 3 & 46492.17 \\
\hline $14381.92 \pm 0.01$ & 17 & $46512.17^{*}$ \\
\hline $14402.38 \pm 0.10$ & 4 & 46532.63 \\
\hline $14408.95 \pm 0.04$ & 5 & $46539.20^{*}$ \\
\hline $14450.53 \pm 0.08$ & 5 & 46580.78 \\
\hline $14455.32 \pm 0.16$ & 4 & 46585.57 \\
\hline $14491.71 \pm 0.08$ & 21 & 46621.96 \\
\hline $14501.68 \pm 0.04$ & 6 & $46631.93^{*}$ \\
\hline $14508.44 \pm 0.03$ & 14 & 46638.69 \\
\hline $14537.23 \pm 0.03$ & 8 & $46667.48^{*}$ \\
\hline $14550.53 \pm 0.02$ & 12 & 46680.78 \\
\hline $14621.56 \pm 0.29$ & 6 & 46751.81 \\
\hline $14620.55 \pm 0.73$ & 8 & 46750.80 \\
\hline $14646.73 \pm 0.03$ & 3 & $46776.98^{*}$ \\
\hline $14660.41 \pm 0.07$ & 12 & $46790.66^{*}$ \\
\hline $14710.96 \pm 0.04$ & 3 & $46841.21^{*}$ \\
\hline $14730.15 \pm 0.04$ & 7 & 46860.40 \\
\hline $14734.94 \pm 0.03$ & 4 & $46865.19^{*}$ \\
\hline $14783.56 \pm 0.03$ & 2 & 46913.81 \\
\hline $14856.83 \pm 0.02$ & 5 & $46987.08^{*}$ \\
\hline $14877.13 \pm 0.04$ & 1 & 47007.38 \\
\hline $14900.71 \pm 0.09$ & 1 & 47030.96 \\
\hline $14934.40 \pm 0.04$ & 1,4 & 47064.65 \\
\hline $14949.91 \pm 0.05$ & 1,1 & 47080.16 \\
\hline $15003.22 \pm 0.04$ & 1,4 & 47133.47 \\
\hline $14998.53 \pm 0.03$ & 2 & 47128.78 \\
\hline $15012.54 \pm 0.29$ & 3 & 47142.79 \\
\hline $15023.91 \pm 0.07$ & 1 & 47154.16 \\
\hline $15054.02 \pm 0.04$ & 3 & 47184.27 \\
\hline $15061.42 \pm 0.11$ & 3 & 47191.67 \\
\hline $15066.53 \pm 0.07$ & 1 & $47196.78^{*}$ \\
\hline $15123.40 \pm 0.05$ & 2 & 47253.65 \\
\hline $15133.38 \pm 0.04$ & 3 & $47263.63^{*}$ \\
\hline $15142.22 \pm 0.03$ & 7 & $47272.47^{*}$ \\
\hline $15150.43 \pm 0.04$ & 9 & $47280.68^{*}$ \\
\hline $15157.55 \pm 0.05$ & 15 & $47287.80^{*}$ \\
\hline $15163.31 \pm 0.05$ & 18 & 47293.56 \\
\hline $15167.83 \pm 0.07$ & 20 & 47298.08 \\
\hline
\end{tabular}




\begin{tabular}{|c|c|c|}
\hline $15173.13 \pm 0.06$ & 12 & 47303.38 \\
\hline $15178.65 \pm 0.06$ & 5 & 47308.90 \\
\hline $15183.66 \pm 0.06$ & 3 & 47313.91 \\
\hline $15188.65 \pm 0.12$ & 3 & 47318.90 \\
\hline $15193.53 \pm 0.11$ & 2 & 47323.78 \\
\hline $15270.61 \pm 0.05$ & 41 & 47400.86 \\
\hline $15307.14 \pm 0.13$ & 5 & 47437.39 \\
\hline $15355.03 \pm 0.21$ & 6 & 47485.28 \\
\hline $15458.19 \pm 0.20$ & 7 & 47588.44 \\
\hline $15519.28 \pm 0.07$ & 16 & 47649.53 \\
\hline $15596.78 \pm 0.11$ & 16 & 47727.03 \\
\hline $15697.77 \pm 0.11$ & 16 & 47828.02 \\
\hline $15744.52 \pm 0.12$ & 7 & 47874.77 \\
\hline $15776.03 \pm 0.09$ & 6 & 47906.28 \\
\hline $15812.64 \pm 0.04$ & 43 & 47942.89 \\
\hline $15825.23 \pm 0.10$ & 6 & 47955.48 \\
\hline $16028.37 \pm 0.09$ & 11,1 & 48158.62 \\
\hline $16102.39 \pm 0.11$ & 9,1 & 48232.64 \\
\hline $16255.67 \pm 0.11$ & 8,3 & 48385.92 \\
\hline $16227.49 \pm 0.19$ & 2 & 48357.74 \\
\hline $16244.84 \pm 0.07$ & 3 & 48375.09 \\
\hline $16388.49 \pm 0.86$ & 6 & 48518.74 \\
\hline $16760.15 \pm 0.05$ & 87 & 48890.40 \\
\hline $16831.37 \pm 0.09$ & 35 & 48961.62 \\
\hline $16855.36 \pm 0.31$ & 7 & 48985.61 \\
\hline $16893.81 \pm 0.05$ & 75 & 49024.06 \\
\hline $16905.45 \pm 0.11$ & 11 & 49035.70 \\
\hline $16955.19 \pm 0.29$ & 3 & 49085.44 \\
\hline $16973.25 \pm 0.18$ & 3 & 49103.50 \\
\hline $17249.07 \pm 0.07$ & 1 & 49379.32 \\
\hline $17274.30 \pm 0.04$ & 1 & 49404.55 \\
\hline $17307.63 \pm 0.19$ & 1 & 49437.88 \\
\hline $17335.61 \pm 0.06$ & 10 & 49465.86 \\
\hline $17409.26 \pm 0.05$ & 2 & 49539.51 \\
\hline $17470.06 \pm 0.15$ & 2 & 49600.31 \\
\hline $17481.72 \pm 0.05$ & 4 & 49611.97 \\
\hline $17512.20 \pm 0.33$ & 3 & 49642.45 \\
\hline $17541.69 \pm 0.06$ & 5 & 49671.94 \\
\hline $17561.73 \pm 0.05$ & 3 & 49691.98 \\
\hline $17594.20 \pm 0.93$ & 3 & 49724.45 \\
\hline $17604.26 \pm 0.19$ & 5 & 49734.51 \\
\hline $17630.67 \pm 0.14$ & 3 & 49760.92 \\
\hline $17705.35 \pm 0.11$ & 5 & 49835.60 \\
\hline $17729.28 \pm 0.05$ & 8 & 49859.53 \\
\hline $17741.18 \pm 0.06$ & 4 & 49871.43 \\
\hline $17764.80 \pm 0.18$ & 4 & 49895.05 \\
\hline $17783.24 \pm 0.32$ & 3 & 49913.49 \\
\hline $17918.52 \pm 0.05$ & 5,5 & 50048.77 \\
\hline $17958.15 \pm 0.08$ & 5 & 50088.40 \\
\hline
\end{tabular}




\begin{tabular}{l|l|l}
$18009.10 \pm 0.22$ & 1 & 50139.35 \\
$18045.01 \pm 0.18$ & 3 & 50175.26 \\
$18073.12 \pm 0.09$ & 3 & 50203.37 \\
$18110.46 \pm 0.08$ & 3 & 50240.71 \\
$18190.20 \pm 0.14$ & 3 & 50320.45 \\
$18222.99 \pm 0.45$ & 3 & 50353.24 \\
$18245.61 \pm 0.13$ & 1 & 50375.86 \\
$18276.69 \pm 0.07$ & 2 & 50406.94 \\
$18308.66 \pm 0.06$ & 1 & 50438.91 \\
$18351.08 \pm 0.08$ & 1 & 50481.33
\end{tabular}

\section{Conclusion}

Extensive scans for new autoionizing states have been performed as the first application of the new atomic beam unit, PISA, of the ISOLDE RILIS laboratory. A total of 98 new AIS were found. We propose 13 new ionization schemes which are particularly well suited for convenient operation of the ISOLDE RILIS. A thorough evaluation of the relative performance of these ionization schemes should be conducted using a standard ISOLDE hot cavity laser ion source, as described in section 5. Once these final measurements will have been performed, the ISOLDE RILIS will be able to provide laser ionized europium, whenever the demand arises.

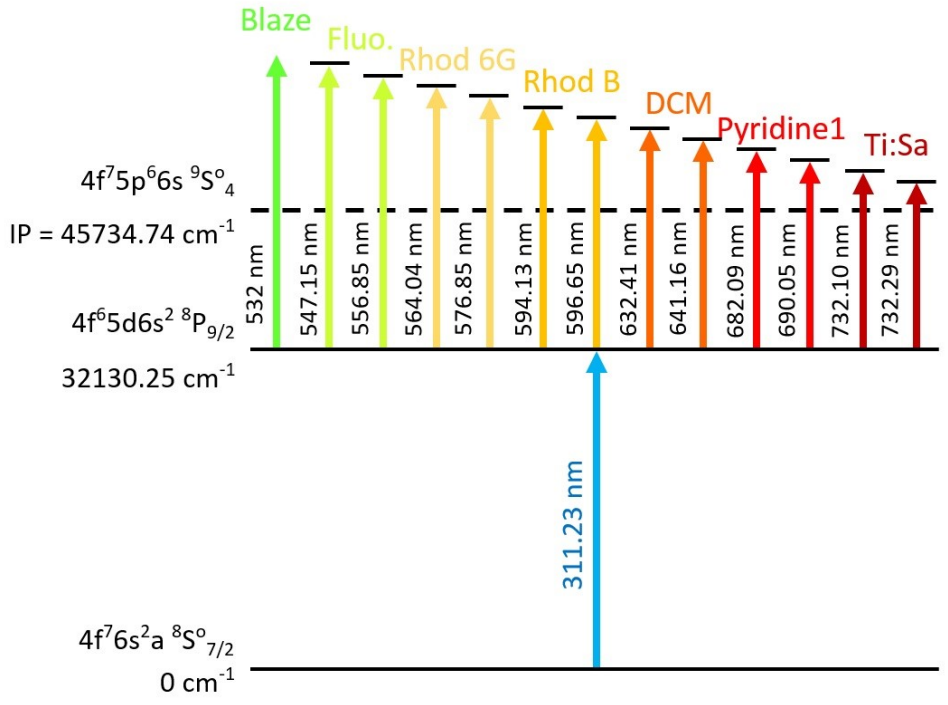

Fig. 4 Proposed laser ionization schemes for europium (all except 'Blaze' are leading to AIS). The two most dominant peaks of each scanning range were chosen for the proposed schemes. Vacuum wavelengths are given. 


\section{Outlook}

In order to finalize the scheme development, time with an ISOLDE target and ion source assembly (on-line or off-line) will be necessary. The following tests should be performed in order to identify the optimal scheme: saturation curves for the first step and second step transitions shown in Figure 4; relative efficiency measurements at the typical conditions of the hot cavity ion source. Additionally the schemes with a transition to an AIS as last step should be compared to the scheme with a non resonant last step at $532 \mathrm{~nm}$. A comparison of the surface/laser ion ratios is a reliable means of evaluating the relative effectiveness of each ionization scheme. In the case of the use of the $40 \mathrm{~W} 532 \mathrm{~nm}$ laser, care should be taken to evaluate any misleading enhancement of the ion rate due to thermal effects or non-resonant ionization of molecular compounds. The former can be studied by time-delaying the first step laser pulse with respect to the $532 \mathrm{~nm}$ laser and performing all scheme comparisons with the $532 \mathrm{~nm}$ laser still on. The latter will require a more selective means of analyzing the ion beam constituents, such as the ISOLTRAP MR-Tof-MS [27].

\section{Acknowledgments}

The work was supported by the European Union's Seventh Framework Programme for Research, Technological Development and Demonstration under Grant Agreement 267194 (COFUND).

\section{References}

1. Fedosseev, V. N., Berg, L.-E., Fedorov, D. V., Fink, D., Launila, O. J., Losito, R., Marsh, B. A., Rossel, R. E., Rothe, S., Seliverstov, M. D., Sjödin, A. M., Wendt, K. D. A.: Upgrade of the resonance ionization laser ion source at ISOLDE on-line isotope separation facility: New lasers and new ion beams; Review of Scientific Instruments, vol. 83, 02A903 (2012), doi:10.1063/1.3662206

2. Rothe, S., Day Goodacre, T., Fedorov, D.V., Fedosseev, V.N., Marsh, B.A., Molkanov, P.L., Rossel, R.E., Seliverstov, M.D., Veinhard, M., Wendt, K.D.A.: Laser ion beam production at CERN-ISOLDE: New features - More possibilities; Nuclear Instruments and Methods in Physics Research Section B: Beam Interactions with Materials and Atoms, vol. 376, (2016), p. 91-96, doi:10.1016/j.nimb.2016.02.024

3. Marsh, B. A., Fedosseev, V. N., Fink, D. A., Day Goodacre, T., Rossel, R. E., Rothe, S., Fedorov, D. V., Imai, N., Seliverstov, M. D., Molkanov, P.: RILIS applications at CERN/ISOLDE; Hyperfine Interactions, vol. 227:1,(2014), p. 101-111, doi:10.1007/s10751-014-1051-6

4. Kugler, Erich: The ISOLDE facility; Hyperfine Interactions, vol 129:1, (2000), p. 23-42, doi:10.1023/A:1012603025802

5. NIST periodic table of the elements: https://www.nist.gov/pml/periodic-table-elements (downloaded 17.10.2016)

6. Nakhate, S.G., Razvi, M.A.N., Connerade, J.P., Ahmad, S.A.: Investigation of Rydberg states of the europium atom using resonance ionization spectroscopy; Journal of Physics B: Atomic, Molecular and Optical Physics, vol. 33(22):5191, (2000), doi:10.1088/0953-4075/33/22/319

7. Kluge, H.-J.: Isolde user's guide; CERN, Genève, Switzerland, 1986

8. É.Ya. Zandberg and N.I. Ionov: Surface ionization; Soviet Physics Uspekhi,vol. 2(2):255, (1959), doi:10.1070/PU1959v002n02ABEH003123

9. Sato, T.K., Asai, M., Borschevsky, A., Stora, T., Sato, N., Kaneya, Y., Tsukada, K., Düllmann, Ch.E., Eberhardt, K., Eliav, E., Ichikawa, S., Kaldor, U., Kratz, J.V., Miyashita, S., Nagame, Y., Ooe, K., Osa, A., Renisch, D., Runke, J., Schadel, M., Thorle-Pospiech, P., Toyoshima, A., Trautmann, N.: Measurement of the first ionization potential of lawrencium, element 103; Nature, vol. 520, (2015), p. 209211 doi:10.1038/nature 14342

10. Jading, Y., Catherall, R., Fedoseyev, V.N., Jokinen, A., Jonsson, O.C., Kautzsch, T., Klöckl, I., Kratz, K.-L., Kugler, E., Lettry, J., Mishin, V.I., Ravn, H.L., Scheerer, F., Tengblad, O., Van Duppen, P., Walters, W.B., Wöhr, A.: Production of radioactive Ag ion beams with a chemically selective laser ion 
source; Nucl. Instrum. and Meth. Phys. Research B, vol. 126, (1997), p. 76-80 doi:10.1016/S0168583X(96)01018-X

11. Rothe, S., Catherall, R., Crepieux, B., Day Goodacre, T., Fedosseev, V.N., Giles, T., Marsh, B.A., Ramos, J.P., Rossel, R.E.: Advances in surface ion suppression from RILIS: Towards the Time-of-Flight Laser Ion Source (ToF-LIS); Nuclear Instruments and Methods in Physics Research Section B: Beam Interactions with Materials and Atoms, vol. 376, (2016), p. 86-90, doi:10.1016/j.nimb.2016.02.060

12. Schwellnus, F., Catherall, R., Crepieux, B., Fedosseev, V.N., Marsh, B.A., Mattolat, Ch., Menna, M., Österdahl, F.K., Raeder, S., Stora, T., Wendt, K.: Study of low work function materials for hot cavity resonance ionization laser ion sources; Nucl. Instrum. and Meth. Phys. Research B, vol. 267, (2009), p. 1856-1861, doi:10.1016/j.nimb.2009.02.068

13. Fink, D.A., Richter, S.D., Blaum, K., Catherall, R., Crepieux, B., Fedosseev, V.N., Gottberg, A., Kron, T., Marsh, B.A., Mattolat, C., Raeder, S., Rossel, R.E., Rothe, S., Schwellnus, F., Seliverstov, M.D., Sjödin, M., Stora, T., Suominen, P., Wendt, K.D.A.: On-line implementation and first operation of the Laser Ion Source and Trap at ISOLDE/CERN; Nuclear Instruments and Methods in Physics Research Section B: Beam Interactions with Materials and Atoms, vol. 344, (2015), p. 83-95, doi:10.1016/j.nimb.2014.12.007

14. Alkhazov, G.D. , Barzakh, A.E., Berlovich, É.I., Denisov, V.P., Dernyatin, A.G., Ivanov, V.S., Zherikhin, A.N., Kompanets, O.N., Letokhov, V.S., Mishin, V.I., Fedoseev, V.N.: High-resolution laser photoionization spectroscopy of radioactive europium isotopes; Sov. Phys. JETP, vol. 59(4), (1984), p. 729-736

15. Nakhate, S.G., Razvi, M.A.N., Bhale, G.L., Ahmad, S.A.: New odd-parity high-lying energy levels of the europium atom by resonance ionization spectroscopy; Journal of Physics B: Atomic, Molecular and Optical Physics, vol. 29(8):1439, (1996)

16. Rothe, S.: Improvement of the precision and efficiency of the ISOLDE laser ion source RILIS; Technical Report CERN-EDMS-1721870 v.1, CERN, Geneva, (2011), https://edms.cern.ch/ document/1721870/1

17. Chrysalidis, K.: Resonance ionization spectroscopy of europium: the first application of the PISA at ISOLDE-RILIS; Master Thesis, Johannes Gutenberg-Universität Mainz, (2016), http: //cds . cern. $\mathrm{ch} / \mathrm{record} / 2227955$

18. Mattolat, C., Rothe, S., Schwellnus, F., Gottwald, T., Raeder, S., Wendt, K.: An All-Solid-State High Repetiton Rate Titanium:Sapphire Laser System For Resonance Ionization Laser Ion Sources; AIP Conference Proceedings, vol. 1104, (2009), p. 114-119, doi:10.1063/1.3115586

19. Rothe, S., Marsh, B.A., Mattolat, C., Fedosseev, V.N., Wendt, K.: A complementary laser system for ISOLDE RILIS; Journal of Physics: Conference Series, vol. 312(5), (2011), http://stacks .iop. org $/ 1742-6596 / 312 / i=5 / a=052020$

20. Naubereit, P.: Weiterentwicklung eines weitabstimmbaren Titan:Saphir-Lasers und sein Einsatz zur Spektroskopie hochliegender Resonanzen in Holmium; Master Thesis, Johannes GutenbergUniversität Mainz, (2014)

21. Fedosseev, V.N., Marsh, B.A., Fedorov, D.V., Köster, U., Tengborn, E.: Ionization Scheme Development at the ISOLDE RILIS; Hyperfine Interactions, vol. 162, (2005), p. 15-27, doi:10.1007/s10751005-9204-2

22. Kron, T.: Konzeption, Aufbau und Test einer Referenzzelle für die resonante Laserionisation; Diploma thesis, Johannes Gutenberg-Universität Mainz, (2011)

23. Kron, T., Ferrer-Garcia, R., Lecesne, N., Sonnenschein, V., Raeder, S., Rossnagel, J., Wendt, K.: Control of RILIS lasers at IGISOL facilities using a compact atomic beam reference cell; Hyperfine Interactions, vol. 216, (2013), p. 53-58, doi:10.1007/s10751-012-0756-7

24. Ross, K.J., Sonntag, B.: High temperature metal atom beam sources; Rev. Sci. Instrum., vol. 66(9), (1995), p. 4409-4433, doi:10.1063/1.1145337

25. A. Kramida, Yu. Ralchenko, J. Reader and NIST ASD Team. NIST Atomic Spectra Database (ver. 5.3), [Online] Available: http://physics.nist.gov/asd [2016, August 5]. National Institute of Standards and Technology, Gaithersburg, MD., 2015

26. Bhattacharyya, S., D’Souza, R., Rao, P.M., Razvi, M.A.N.: Investigation of new odd-parity autoionization Rydberg levels of neutral europium; Spectrochimica Acta Part B: Atomic Spectroscopy, vol. 58(3), (2003), p. 469-478, doi:10.1016/S0584-8547(03)00003-X

27. Wolf, R., Beck, D., Blaum, K., et al.: On-line separation of short-lived nuclei by a multi-reflection time-of-flight device, Nucl. Instr. Meth. A, vol. 686, (2012), p. 82-90, doi:10.1016/j.nima.2012.05.067 